\title{
Hyperglycemia induces differential change in oxidative stress at gene expression and functional levels in HUVEC and HMVEC
}

Hemang Patel ${ }^{1 *}$, Juan Chen ${ }^{1}$, Kumuda C Das ${ }^{2}$ and Mahendra Kavdia ${ }^{1}$

\begin{abstract}
Background: Endothelial dysfunction precedes pathogenesis of vascular complications in diabetes. In recent years, the mechanisms of endothelial dysfunction were investigated to outline strategies for its treatment. However, the therapies for dysfunctional endothelium resulted in multiple clinical trial failures and remain elusive. There is a need for defining hyperglycemia-induced endothelial dysfunction with both generic and specific dysfunctional changes in endothelial cells (EC) using a systems approach. In this study, we investigated hyperglycemia-induced endothelial dysfunction in HUVEC and HMVEC. We investigated hyperglycemia-induced functional changes (superoxide $\left(\mathrm{O}_{2}{ }^{-}\right)$, and hydrogen peroxide $\left(\mathrm{H}_{2} \mathrm{O}_{2}\right)$ production and mitochondrial membrane polarization) and gene expression fingerprints of related enzymes (nitric oxide synthase, NAD(P)H oxidase, and reactive oxygen species (ROS) neutralizing enzymes) in both ECs.

Method: Gene expression of NOS2, NOS3, NOX4, CYBA, UCP1, CAT, TXNRD1, TXNRD2, GPX1, NOX1, SOD1, SOD2, PRDX1, 18s, and RPLPO were measured using real-time PCR. $\mathrm{O}_{2}^{-}$production was measured with dihydroethidium (DHE) fluorescence measurement. $\mathrm{H}_{2} \mathrm{O}_{2}$ production was measured using Amplex Red assay. Mitochondrial membrane polarization was measured using JC-10 based fluorescence measurement.

Results: We showed that the $\mathrm{O}_{2}^{-}$levels increased similarly in both ECs with hyperglycemia. However, these endothelial cells showed significantly different underlying gene expression profile, $\mathrm{H}_{2} \mathrm{O}_{2}$ production and mitochondrial membrane polarization. In HUVEC, hyperglycemia increased $\mathrm{H}_{2} \mathrm{O}_{2}$ production, and hyperpolarized mitochondrial membrane. ROS neutralizing enzymes SOD2 and CAT gene expression were downregulated. In contrast, there was an upregulation of nitric oxide synthase and $\mathrm{NAD}(\mathrm{P}) \mathrm{H}$ oxidase and a depolarization of mitochondrial membrane in HMVEC. In addition, ROS neutralizing enzymes SOD1, GPX1, TXNRD1 and TXNRD2 gene expression were significantly upregulated in high glucose treated HMVEC.

Conclusion: Our findings highlighted a unique framework for hyperglycemia-induced endothelial dysfunction. We showed that multiple pathways are differentially affected in these endothelial cells in hyperglycemia. High occurrences of gene expression changes in HMVEC in this study supports the hypothesis that microvasculature precedes macrovasculature in epigenetic regulation forming vascular metabolic memory. Identifying genomic phenotype and corresponding functional changes in hyperglycemic endothelial dysfunction will provide a suitable systems biology approach for understanding underlying mechanisms and possible effective therapeutic intervention.
\end{abstract}

Keywords: Endothelial dysfunction, Microvascular dysfunction, Systems biology, Oxidative stress, Hyperglycemia, HUVEC, HMVEC, Vascular metabolic memory

\footnotetext{
* Correspondence: hemang@wayne.edu

'Department of Biomedical Engineering, Wayne State University, 2322

Engineering, 5050 Anthony Wayne Dr., Detroit, Ml 48202, USA

Full list of author information is available at the end of the article
} 


\section{Background}

Diabetes, a complex metabolic syndrome, is a rapidly growing public health burden in both developed and developing countries. Among all pathophysiologies associated with diabetes, micro and macrovascular complications are implicated in most conditions leading to morbidity and mortality in diabetic patients [1]. Hyperglycemic condition associated with diabetes dysregulates endothelial function that leads to initiation and propagation of vascular complications and dysfunction [2,3]. The understanding and amelioration of endothelial dysfunction is important for diabetic vascular complications.

The onset of endothelial dysfunction begins with disruption of balance amongst vasorelaxation and vasoconstriction factors. Under hyperglycemic condition, an increase in intracellular reactive oxygen species (ROS) is responsible for pathophysiological changes including nitric oxide (NO) synthesis inhibition, vascular inflammation, insulin resistance, neovascularization, leukocyte adhesion, and protein and macromolecule glycation [4-6]. Pharmacological therapies including antioxidants, vitamin E, Larginine, calcium antagonists, $\beta$-blockers, renin-angiotensin system inhibitors, statins, insulin-resistance improving drugs, erythropoietin, and tetrahydrobiopterin have been shown to ameliorate endothelial dysfunction [2,5,7-9]. However, their efficacy on treating dysfunctional endothelium varies with different disorders and in different parts of vasculature [2,5,7-9]. Several of the clinical trials with antioxidants have failed to show benefits even though in vitro and animal studies have shown significant improvement $[6,9]$. Our understanding of the mechanisms of hyperglycemia-induced oxidative stress and resulting endothelial cell dysfunction from a systems perspective is lacking. While the reason for justifying differential efficacies of therapeutic strategies remains unclear, these findings have raised the need for improving the understanding for hyperglycemia-induced pathogenesis of endothelial dysfunction in different parts of vasculature.

In normal physiology, endothelial cells (EC) regulate vascular homeostasis through $\mathrm{NO}$ production and its bioavailability [10]. Even though critical for wide ranges of cell signaling and cell-cell communication processes, NO is susceptible to inactivation through intracellular superoxide $\left(\mathrm{O}_{2}^{-}\right)$[10]. In hyperglycemia, intracellular $\mathrm{O}_{2}^{-}$increases from sources including $\mathrm{NAD}(\mathrm{P}) \mathrm{H}$ oxidase family enzymes, xanthine oxidase, cyclooxygenase, uncoupled constitutive nitric oxide synthase (eNOS), mitochondrial electron transport, glucose oxidase, and lipooxygenase [6,11-14]. Intracellular $\mathrm{O}_{2}^{-}$is a relatively short-lived species, which can get dismutated by superoxide dismutase (SOD) enzyme and self-dismutation to hydrogen peroxide $\left(\mathrm{H}_{2} \mathrm{O}_{2}\right)$ in addition to its rapid reaction with NO.

Unlike $\mathrm{O}_{2}{ }^{-}, \mathrm{H}_{2} \mathrm{O}_{2}$ is more stable ROS [15]. High glucose exposure increases $\mathrm{H}_{2} \mathrm{O}_{2}$, which is a result of rapid dismutation of $\mathrm{O}_{2}^{-}$in mitochondria and an increase in $\mathrm{NAD}(\mathrm{P}) \mathrm{H}$ oxidase-4 (NOX4) activity in cytosol $[16,17]$. The lower level of $\mathrm{H}_{2} \mathrm{O}_{2}$ causes vasorelaxation along with induction and activation of nitric oxide synthase (NOS) $[15,18]$, whereas the higher level of $\mathrm{H}_{2} \mathrm{O}_{2}$ promote vasoconstriction and causes oxidative damage to the vasculature [18]. During oxidative stress condition, the intracellular $\mathrm{H}_{2} \mathrm{O}_{2}$ levels are tightly regulated through i) a direct involvement of catalase, peroxiredoxin and thioredoxin enzyme networks, and ii) an indirect involvement from uncoupling proteins, and Nrf-2 expression $[19,20]$. Therefore, endothelial function is regulated though a complex network of regulation in $\mathrm{NO}$ production, $\mathrm{O}_{2}^{-}$ production and dismutation, and peroxide clearance.

For a generic understanding of hyperglycemia-mediated oxidative stress and endothelial dysfunction, the current trend in literature emphasizes the studying and understanding of individual sources of endothelial dysfunction in a specific type of endothelial cells or vasculature segment. In normal physiology, endothelial cells originated from different organs and parts of vasculature express different functional characteristics that are based on endothelial function, gene expression, and proteomic profile at homeostasis [21-23]. Such functional differences in endothelial cells can be precursors of their variable behavior under both physiological and pathophysiological conditions [24].

Hyperglycemia has been shown to increase $\mathrm{O}_{2}{ }^{-}$production and induce endothelial dysfunction. However, the production and involvement of $\mathrm{O}_{2}^{-}$sources varies across ECs from different parts of vasculature [25-28]. In human glomerular endothelial cells (HGEC) and human aortic endothelial cells (HAEC), the major source of hyperglycemia-induced oxidative stress and $\mathrm{O}_{2}{ }^{-}$ production is uncoupled eNOS and $\mathrm{NAD}(\mathrm{P}) \mathrm{H}$ oxidase, respectively [26,28]. Hyperglycemia-induced endothelial dysfunction is also differentially regulated in ECs from different part of the vasculature. Karabach et al. [29] showed that HUVEC and EA.hy.926 have significantly different cell viability and $\mathrm{O}_{2}^{-}$formation in hyperglycemia. Pala et al. [30] showed that HAEC and HMVEC have differential dipeptidyl peptidase-4 expression and activity levels in hyperglycemia. Wang et al. [24] showed that endothelial cells derived from myocardial microvasculature and aorta of type 2 diabetic rats differentially expressed growth factors and impaired angiogenesis only in myocardial microvascular endothelial cells.

These studies show a need for the understanding of mechanisms for the differences in hyperglycemia-induced endothelial cell functional changes across the vasculature. Further studying ECs from different parts of the vasculature will enhance the system wide understanding for hyperglycemia-induced vascular dysfunction [31]. In this study, we investigated hyperglycemia-induced endothelial 
dysfunction in HUVEC and HMVEC. To compare changes in functional behavior of both cell types, levels of $\mathrm{O}_{2}^{-}$, $\mathrm{H}_{2} \mathrm{O}_{2}$, and mitochondrial membrane polarization were measured following 24 hours of $25 \mathrm{mM}$ D-glucose exposure. In addition, we measured gene expression changes important to these functional changes including nitric oxide synthase enzymes (NOS2 and NOS3), NAD(P)H oxidase enzymes (NOX1, NOX4, and CYBA), ROS neutralizing enzymes such as superoxide dismutase (SOD1 and SOD2), catalase (CAT), peroxiredoxin (PRDX1), glutathione peroxidase 1 (GPX1) and thioredoxin reductase 1 and 2 (TXNRD1 and TXNRD2), oxidative stress activated transcription factor, Nrf-2, (NFE2L2), and uncoupling protein 1(UCP1). Findings from this study outline a relationship between functional changes and the underlying genomic phenotype to improve understanding of differential effects of hyperglycemia on endothelial cells.

\section{Methods}

\section{Cell culture and experimental protocol}

Primary HUVEC and HMVEC were purchased from Lonza, MD. HUVEC and HMVEC were grown using EGM-2 media supplemented with Bullet kit (Lonza, MD). Media was changed every 48 hours until cells reached 80 to $90 \%$ confluency. At confluency, cells were either subcultured or used for experiments. For all experiments, cells growing at passage either 4 or 5 were used and experiments were carried out using M199 media supplemented with low serum growth supplement kit (Life Tech, CA). This media was also used as control and had 5.6 mM D-glucose. For high glucose treatment, D-glucose was added to M199 for a final concentration of $25 \mathrm{mM}$ (HG-M199). For experiments, HUVEC and HMVEC were seeded into separate 6 well plates. After 24 hours of seeding, half of the sample wells in 6 well plates were treated with HG-M199 media, and the other half were treated with the control media.

\section{$\mathrm{O}_{2}^{-}$measurement using DHE fluorescence}

Dihydroethidium (DHE), was used to measure $\mathrm{O}_{2}^{-}$in HUVEC and HMVEC following 24 hours of treatment with high glucose. At the end of the treatment period, cells were washed and incubated with $5 \mu \mathrm{M}$ DHE in phenol red-free treatment medium for 1 hour. During the incubation period cells, we measured 2-hydroxyethidium (2-OH$\mathrm{E}^{+}$), a specific product from $\mathrm{DHE}$ and $\mathrm{O}_{2}^{-}$interaction, intensity using a microplate reader. Excitation (Ex) of $508 \pm$ $10 \mathrm{~nm}$ and emission (Em) of $560 \pm 20 \mathrm{~nm}$ were used for a specific measurement of $2-\mathrm{OH}-\mathrm{E}^{+}$[32-34]. Alternatively, fluorescence microscopy was also used to capture differences in fluorescence intensities at the end of 1 hour incubation with DHE.

\section{$\mathrm{H}_{2} \mathrm{O}_{2}$ measurement}

After treating cells, media supernatants were collected to measure $\mathrm{H}_{2} \mathrm{O}_{2}$ using Amplex ${ }^{\odot}$ Red based assay (Life Tech, CA). In brief, at the time interval of 3, 6, 9, and 24 hours media supernatants were collected and stored in aliquots at $-80^{\circ} \mathrm{C}$ and different wells were used for each time point. Supernatants were quickly thawed and centrifuged immediately before use. As per manufacturer's instruction, a lower $\mathrm{H}_{2} \mathrm{O}_{2}$ concentration range was used for a standard curve to quantify $\mathrm{H}_{2} \mathrm{O}_{2}$ in supernatants.

\section{Mitochondrial membrane polarization measurement}

JC-10 (Enzo Life Sciences, NY) was used to measure mitochondrial membrane polarization in cells. JC-10 is a cationic fluorophore, which is rapidly taken up by cells and mitochondria due to their negative charge. Inside mitochondria, JC-10 forms J-aggregates which emit fluorescence at $590 \mathrm{~nm}$ (red fluorescence). Remaining JC-10 in cytosol maintains monomeric form and emits fluorescence at $525 \mathrm{~nm}$ (green fluorescence). Uptake levels of JC-10 in mitochondria depend on polarization state of mitochondrial membrane. Hyperpolarized mitochondria have higher uptake of JC-10 compared to depolarized. Following the treatment, cells were washed twice with PBS and then incubated with $1 \mu \mathrm{M}$ JC-10 solution prepared in PR-free M199 media for 15 minutes. After 15 minutes of incubation, cells were incubated with $1 \mu \mathrm{g} / \mathrm{ml}$ Hoescht 33342 (Life technologies, CA) for 10 minutes and then quickly washed with PBS prior to fluorescence imaging and microplate reader based measurements. Microplate reader based measurement for J-monomers and J-aggregates were carried out at $485 \pm 10 \mathrm{~nm}(\mathrm{Ex}) / 516 \pm 10 \mathrm{~nm}(\mathrm{Em})$ and $528 \pm 10 \mathrm{~nm}(\mathrm{Ex}) / 590 \mathrm{~nm} \pm 10(\mathrm{Em})$, respectively.

\section{RNA extraction and reverse transcription}

We used RNeasy mini kit (Qiagen, CA) to extract RNA. During RNA extraction genomic DNA was also removed by DNase I digest treatment. Quantity and purity of extracted RNA samples were analyzed using spectrophotometry prior to storing them in aliquots at $-80^{\circ} \mathrm{C}$. All RNA samples were also analyzed for integrity and genomic DNA contamination using flash gel (Lonza, MD) prior to their use in reverse transcription. Reverse transcription reactions were performed using a high capacity cDNA reverse transcription kit (Life Technologies, CA). As per manufacturer's protocol, $1.5 \mu \mathrm{g}$ of extracted RNA from each treatment and control samples were converted to cDNA in a $20 \mu \mathrm{l}$ reverse transcription reaction. Following reverse transcription, all cDNA samples were stored in aliquots at $-20^{\circ} \mathrm{C}$ until analyzed.

\section{Gene expression analysis}

Real-time PCR was used to check gene expression levels of NOS2, NOS3, NOX4, CYBA, UCP1, CAT, TXNRD1, 
TXNRD2, GPX1, NOX1, SOD1, SOD2, PRDX1, 18s, and RPLP0. Synthesized cDNA from treatment and control groups specific to both HUVEC and HMVEC were used to setup real time-PCR reactions. Gene expression levels of NOS2, NOS3, NOX4, CYBA, 18s and RPLP0 were measured using Taqman gene expression assays (Life Technologies, CA). The rest of the gene expression targets were measured using custom designed primers and SYBR green chemistry. NCBI's Primer-BLAST feature was used to design primer sequences specific to UCP1: 5'-GCTCCAGGTCCAAGGTGAAT-3' and 5' -ACAG CGGTGATTGTTCCCAG-3'; CAT: 5'-AGGGGCCTTT GGCTACTTTG-3' and 5'-ACCCGATTCTCCAGCAA CAG-3'; TXNRD1: 5 '-GGAACTAGATGGGGTCTCGG$3^{\prime}$ and $5^{\prime}$-TCTTGCAGGGCTTGTCCTAA-3'; TXNRD2: 5'-GGTGGACTACGTGGAACCTT-3' and 5' ${ }^{\prime}$-TCTGCC ATCTTCCTCCAGTCA-3'; GPX1: 5'-CCGGGACTACA CCCAGATGA-3' and 5'-CGTTCTCCTGATGCCCA AAC-3'; PRDX1: 5' 'TCCTTTGGTATCAGACCCGA-3' and 5'-TAAAAAGGCCCCTGAACGAG-3'; NOX1: 5'ATCCCCCTGAGTCTTGGAAGT-3' and 5'-CACTTCC ATGCTGAAGCCAC-3'; SOD1: 5' -AGCATTAAAGGAC TGACTGAAGG-3' and 5'-GTCTCCAACATGCCTCTC TTC-3'; and SOD2: 5'-GTTGGGGTTGGCTTGGT 'TTC-3' and 5' - ATAAGGCCTGTTGTTCCTTGC-3'.
All Taqman gene expression assays were setup using Taqman gene expression mastermix (Life Technologies, $\mathrm{CA}$ ), and $75 \mathrm{ng}$ of cDNA, from respective samples in $20 \mu \mathrm{l}$ PCR reactions. Using StepOne Plus System (Life Technologies, $\mathrm{CA}$ ) real-time PCR run was setup as follows: 2 minutes at $50^{\circ} \mathrm{C}$ and then 10 minutes at $95^{\circ} \mathrm{C}$ followed by 36 cycles of 15 seconds at $95^{\circ} \mathrm{C}, 1$ minute at $60^{\circ} \mathrm{C}$. Rest of the gene expression targets were measured in real-time PCR using SYBR green based detection. All SYBR green based PCR reactions were setup using $200 \mathrm{nM}$ of forward and reverse primers, $56.25 \mathrm{ng}$ of cDNA, and Fast SYBR green expression master mix (Life Technologies, CA) in $20 \mu \mathrm{l}$ volume. Real-time PCR reaction compiling $20 \mathrm{sec}-$ onds at $95^{\circ} \mathrm{C}$ followed by 36 cycles of 3 seconds at $95^{\circ} \mathrm{C}$, 20 seconds at annealing temperature of respective primer set, and 20 seconds at $60^{\circ} \mathrm{C}$ steps was used to carry out the reaction. Following each SYBR green based PCR, melt curve analysis and agarose gel based quality check were performed to evaluate the quality and specificity of PCR amplifications. Furthermore, no reverse transcription, and no template controls were also ran for evaluating specificity of PCR amplification.

The cycle threshold $\left(\mathrm{C}_{\mathrm{T}}\right)$ values form all real-time PCR experiments were analyzed using $\Delta \Delta \mathrm{C}_{\mathrm{T}}$ method. Housekeeping genes 18s and RPLP0 were used for normalizing
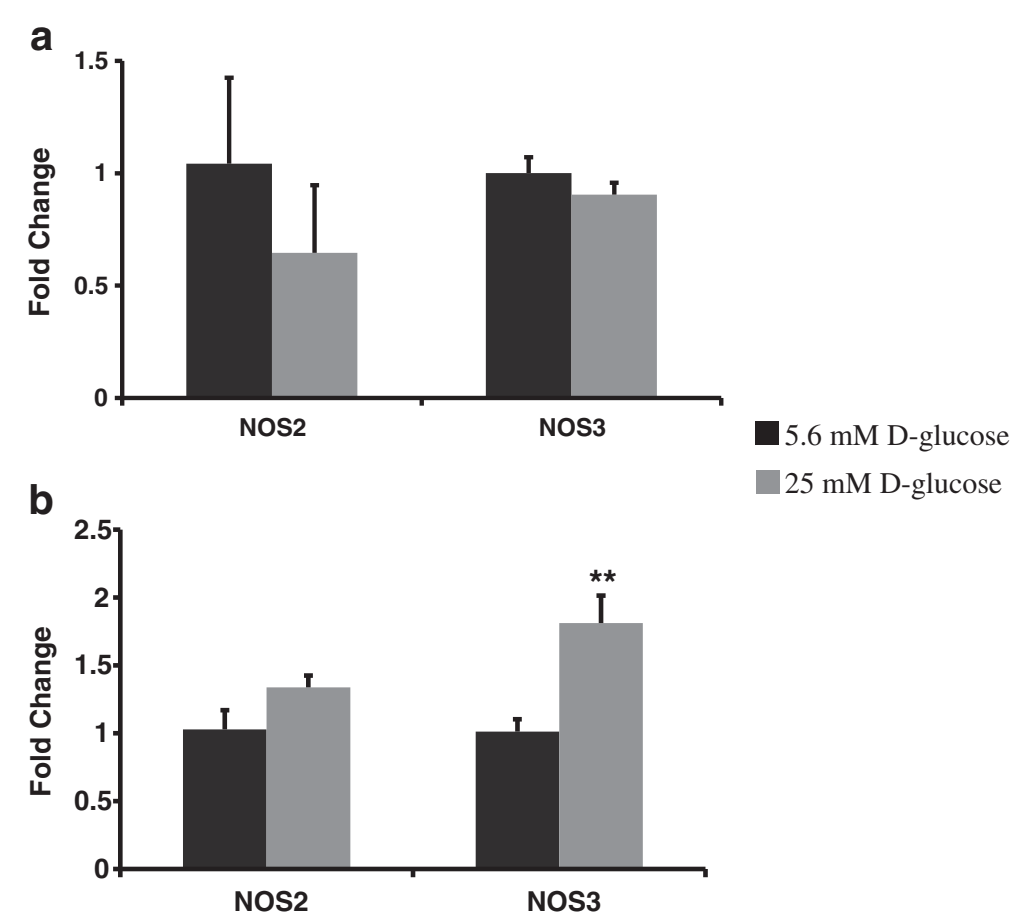

Figure 1 Expression levels of NOS enzymes in HUVEC, and HMVEC after 24 hours of high glucose exposure. Gene expression of NOS2 and NOS3 were measured following 24 hours of HG-M199 exposure to (a) HUVEC and (b) HMVEC. Fold changes were calculated by $2^{-\Delta \Delta C}$ T method using 18s and RPLPO as housekeeping genes and cells grown in M199 media with $5.6 \mathrm{mM}$ D-glucose as control. ${ }^{* *} \mathrm{p} \leq 0.05$ significantly higher than control for respective cells type. 
gene expression from both HUVEC and HMVEC. All gene expression results were presented as normalized fold changes, calculated using $2^{-\Delta \Delta C}$, compared to control (5.6 mM D-glucose).

\section{Data analysis}

All experiments were carried out three times, except for hydrogen peroxide measurements, which had four replicates. Data analyses on all results were carried out using one-way analysis of variance (ANOVA) followed by Fisher's LSD based post-hoc analysis. Comparisons were deemed significant for $\mathrm{p}$-value $\leq 0.05$. All quantified results were presented as mean \pm S.E.M. (standard error of mean) in graphical representation.

\section{Results}

Gene expression of NOS and NOX family enzymes in hyperglycemia was upregulated in HMVEC but not in HUVEC We exposed HUVEC and HMVEC to high glucose for 24 hrs. After 24 hours of exposure, RNA was isolated and synthesized to cDNA for real-time PCR based gene expression measurement. We measured the gene expression levels of NOS and NOX family enzyme, which are sources of NO and superoxide, respectively. As seen in Figure 1a, the gene expression levels of NOS2 and NOS3 were downregulated (though not statistically significant) in HUVEC after high glucose exposure. High glucose exposure to HMVEC increased NOS3 $(\mathrm{p} \leq 0.05)$ and NOS2 (not significant, $\mathrm{p}=$ 0.15 ) expression (Figure 1b). Following high glucose exposure, the expression of NOX family genes did not change in HUVECs (Figure 2a) whereas the expression of NOX1 $(p \leq 0.05)$, NOX4 $(p \leq 0.05)$, and CYBA $(p=0.07)$ (Figure $2 \mathrm{~b}$ ) increased in HMVEC. Thus, high glucose induced significantly different response in NOS and NOX family enzyme in HMVEC and HUVEC.

\section{Hyperglycemia upregulated the gene expression of ROS} and peroxide clearance enzymes in HMVEC whereas it downregulated in HUVEC

After 24 hours of exposure to high glucose, gene expression levels of SOD1, SOD2, CAT, GPX1, TXNRD1, TXNRD2, and PRDX1 were measured to evaluate transcriptional changes leading to ROS and peroxide clearance in HUVEC and HMVEC. We observed an opposite transcription regulation of ROS and peroxide clearance enzymes in high glucose treated HUVEC and HMVEC. As seen in Figure 3a, the expression of SOD2 and CAT was significantly $(\mathrm{p} \leq 0.05)$ downregulated in HUVEC
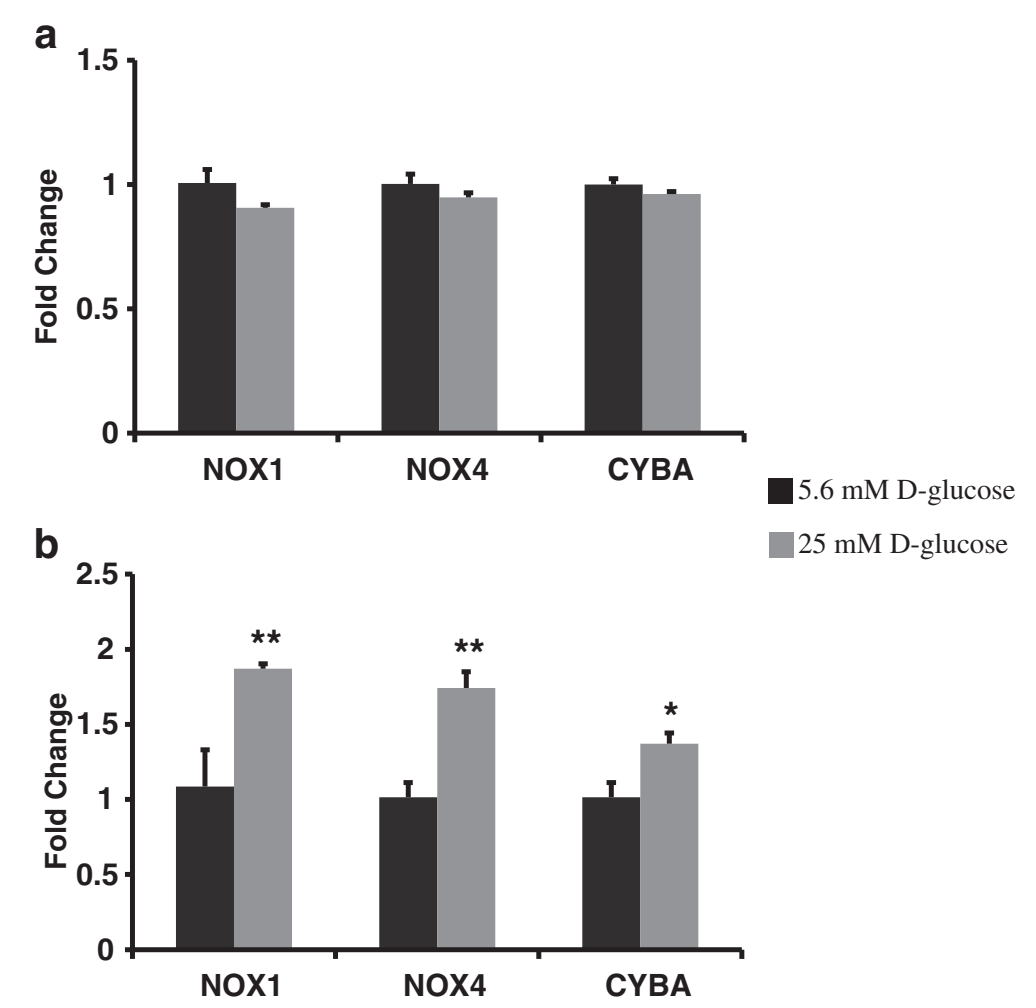

Figure 2 Expression levels of NAD(P)H oxidase family enzymes in a) HUVEC, and) HMVEC cells after 24 hours of high glucose exposure. Gene expression of NOX1, NOX4, and CYBA were measured using real-time PCR in both (a) HUVEC and (b) HMVEC. Fold changes were calculated by $2^{-\triangle \Delta C}$ method using $18 \mathrm{~s}$ and RPLPO as housekeeping genes and cells grown in M199 media with 5.6 mM D-glucose as control. ${ }^{* *} p \leq 0.05$ significantly higher than control for HMVEC. ${ }^{*} p \leq 0.07$ higher than control for HMVEC. 

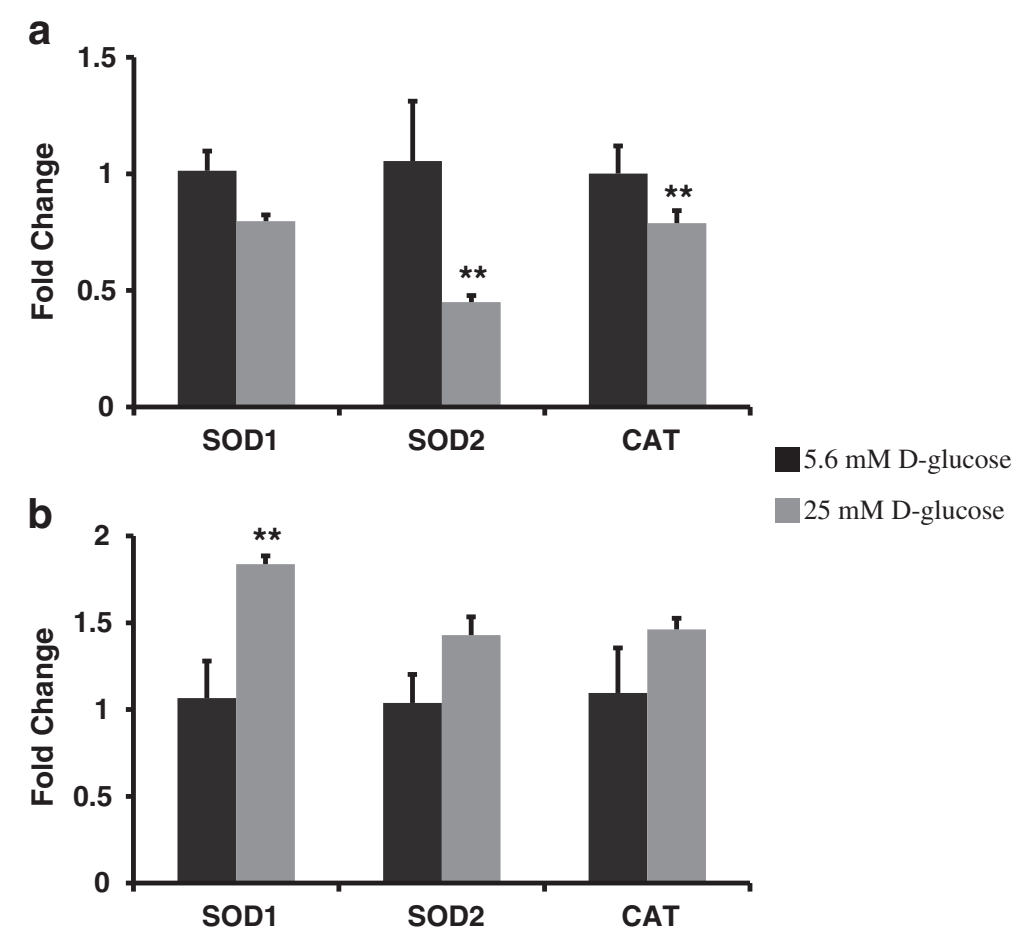

Figure 3 Expression levels of ROS clearance enzymes in HUVEC, and HMVEC cells after 24 hours of high glucose exposure. Gene expression of SOD1, SOD2, and CAT were measured in (a) HUVEC and (b) HMVEC following 24 hours of treatment with HG-M199. Fold changes were calculated by $2^{-\triangle \Delta C}$ method using $18 \mathrm{~s}$ and RPLP0 as housekeeping genes and cells grown in M199 media with 5.6 mM D-glucose as control. ${ }^{* *} \mathrm{p} \leq 0.05$ significantly different than control for respective cells type.

post 24 hours of high glucose exposure. The expression of SOD1 $(p=0.16)$, GPX1 $(p=0.34)$, TXNRD1 $(p=0.11)$, TXNRD2 $(\mathrm{p}=0.39)$ and PRDX1 $(\mathrm{p}=0.11)$ was also downregulated (but not statistically significant) compared to control in HUVEC (Figure 4a). High glucose exposure upregulated gene expression of ROS and peroxide clearance enzymes in HMVEC. The expression of SOD1 ( $\mathrm{p} \leq$ 0.05), GPX1 ( $\mathrm{p} \leq 0.0005)$, TXNRD1 ( $\mathrm{p} \leq 0.05)$ and TXNRD2 $(p \leq 0.05)$ was significantly upregulated in high glucose treated HMVEC (Figures 3b and 4b). Moreover, the expression levels of SOD2 $(p=0.15)$, CAT $(p=0.21)$ and PRDX1 $(p=0.13)$ were also upregulated but not statistically different than the control (Figure $3 \mathrm{~b}$ ) in HMVEC. Thus, there was an overall upregulation in expression of ROS and peroxide clearance enzymes in HMVEC whereas in HUVEC their expression either downregulated or remained unchanged under hyperglycemia.

\section{Hyperglycemia upregulated oxidative stress activated transcription factor (NFE2L2) and UCP1 gene expressions in HMVEC but not in HUVEC}

We measured gene expression of NFE2L2 and UCP1 in high glucose treated HUVEC and HMVEC following 24 hour exposure. NFE2L2 translates to Nrf-2, which is a transcription factor for antioxidant enzymes, to maintain cellular redox state under oxidative stress condition. As seen in Figure 5, hyperglycemia induced a downregulation of NFE2L2 $(\mathrm{p}=0.19)$ in HUVEC whereas it upregulated NFE2L2 expression in HMVEC $(p=0.06)$. Similarly, UCP1, which uncouples the electron transport chain from oxidative phosphorylation and thereby decreases mitochondrial ROS generation, expression was also differentially regulated in both endothelial cells. High glucose exposure induced no change in UCP1 in HUVEC (Figure 5a) whereas the expression of UCP1 was upregulated in $\operatorname{HMVEC~(~} \mathrm{p}=$ 0.06 , Figure $5 b)$.

Hyperglycemia increased intracellular $\mathrm{O}_{2}^{-}$production, in both endothelial cells, that was accompanied with elevated $\mathrm{H}_{2} \mathrm{O}_{2}$ levels in HUVEC and not in HMVEC

In order to understand how changes in these gene expression results in overall cellular ROS generation, we measured $\mathrm{O}_{2}{ }^{-}$and $\mathrm{H}_{2} \mathrm{O}_{2}$, levels in HUVEC and HMVEC. High glucose exposure induced a similar increase in $\mathrm{O}_{2}{ }^{-}$ production in both HUVEC and HMVEC but $\mathrm{H}_{2} \mathrm{O}_{2}$ levels were regulated differently in both endothelial cells. Figure 6 shows the DHE measurement using fluorescence microscopy and a microplate reader. There was an increase in $\mathrm{O}_{2}^{-}$production for both endothelial cells treated with high glucose for 24 hours as shown in DHE fluorescence images (Figure 6a-d). Furthermore, the 


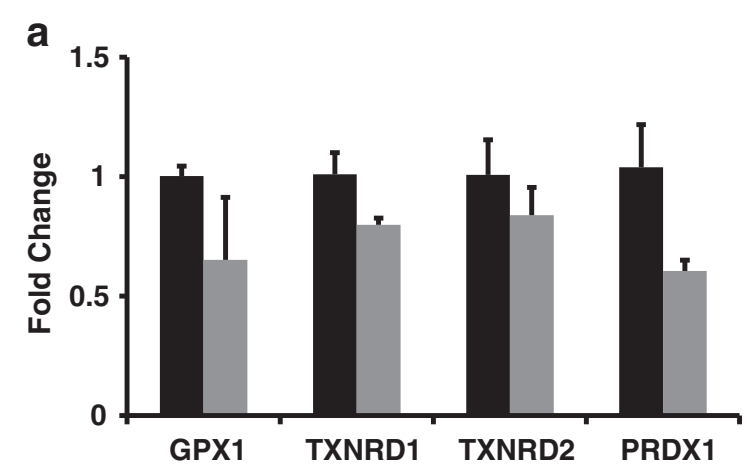

b

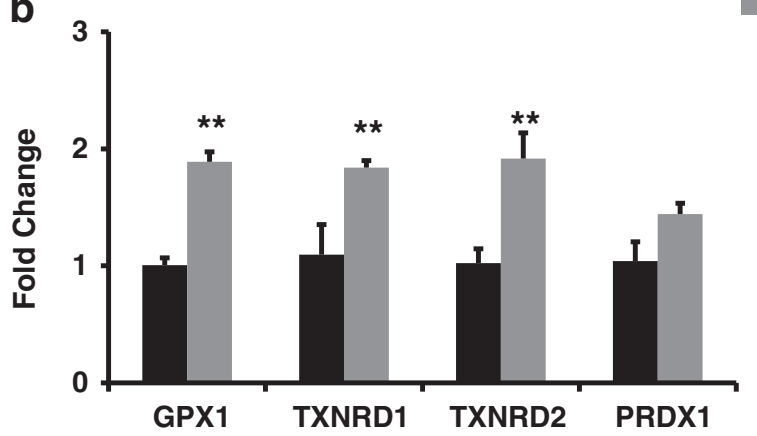

Figure 4 Expression levels of peroxide clearance enzymes in HUVEC, and HMVEC cells after $\mathbf{2 4}$ hours of high glucose exposure. Gene expression of GPX1, TXNRD1, TXNRD2, and PRDX1 were measured in (a) HUVEC and (b) HMVEC following 24 hours of exposure to HG-M199. Fold changes were calculated by $2^{-\triangle \Delta C}$ method using 18 s and RPLPO as housekeeping genes and cells grown in M199 media with 5.6 mM D-glucose as control. ${ }^{* *} \mathrm{p} \leq 0.05$ significantly higher than control for HMVEC.

specific product of DHE and $\mathrm{O}_{2}^{-}$interaction, $2-\mathrm{OH}-\mathrm{E}^{+}$, significantly increased in both HUVEC and HMVEC $(\mathrm{p} \leq 0.01)$ after high glucose exposure (Figure 6e).

Figure 7 shows the $\mathrm{H}_{2} \mathrm{O}_{2}$ levels over 24 hours. Although there was no significant change in $\mathrm{H}_{2} \mathrm{O}_{2}$ levels at initial time points in HUVEC, $\mathrm{H}_{2} \mathrm{O}_{2}$ level at 24 hours was significantly higher than control $(\mathrm{p} \leq 0.006)$ as seen in Figure 7a. On contrary, high glucose treatment did not change $\mathrm{H}_{2} \mathrm{O}_{2}$ level in HMVEC over 24 hours of exposure (Figure $7 \mathrm{~b}$ ). $\mathrm{H}_{2} \mathrm{O}_{2}$ production profiles were similar in controls for both cell types over 24 hours. Basal level of $\mathrm{H}_{2} \mathrm{O}_{2}$ in control was higher in HUVEC than in HMVEC. In addition, $\mathrm{H}_{2} \mathrm{O}_{2}$ production profiles were different and $\mathrm{H}_{2} \mathrm{O}_{2}$ levels were higher in hyperglycemic HUVEC compared to HMVEC.

\section{Hyperglycemia hyperpolarized mitochondrial membrane in HUVEC whereas it depolarized mitochondrial membrane in HMVEC}

To understand the effect of hyperglycemia-induced change in gene expressions and ROS level on mitochondrial activity, we measured mitochondrial membrane polarization in HUVEC and HMVEC over 24 hours using JC-10. As seen in Figure 8a, high glucose treated HUVEC had high red fluorescence because of JC-10 aggregation in mitochondria.
In addition, the ratio of red to green fluorescence was significantly higher in high glucose treated HUVEC compared to control ( $\mathrm{p} \leq 0.05$, Figure $8 b)$. This indicated that mitochondrial membrane hyperpolarized after exposure to hyperglycemia in HUVEC. In HMVEC, high glucose exposure caused lower red fluorescence intensity (Figure 8c) and significantly lower red to green fluorescence ratio $(\mathrm{p} \leq$ 0.05 , Figure $8 \mathrm{~d}$ ) as compared to control. These changes in JC-10 fluorescence indicated that HMVEC mitochondrial membrane depolarized after exposure to hyperglycemia. Thus, high glucose exposure induced a complete opposite trend in mitochondrial membrane polarization in both HUVEC and HMVEC.

\section{Discussion}

An understanding of hyperglycemia-induced endothelial dysfunction is important for therapeutic intervention of vascular complications in diabetes. In this study, we compared the hyperglycemia-related changes in primary human endothelial cells from both umbilical vein (HUVEC) and microvascular (HMVEC) origins. We investigated the regulation of hyperglycemia-induced functional changes and gene expression fingerprints for related enzymes in both ECs. We did not evaluate specific protein expression and activity levels as we observed various sources and 

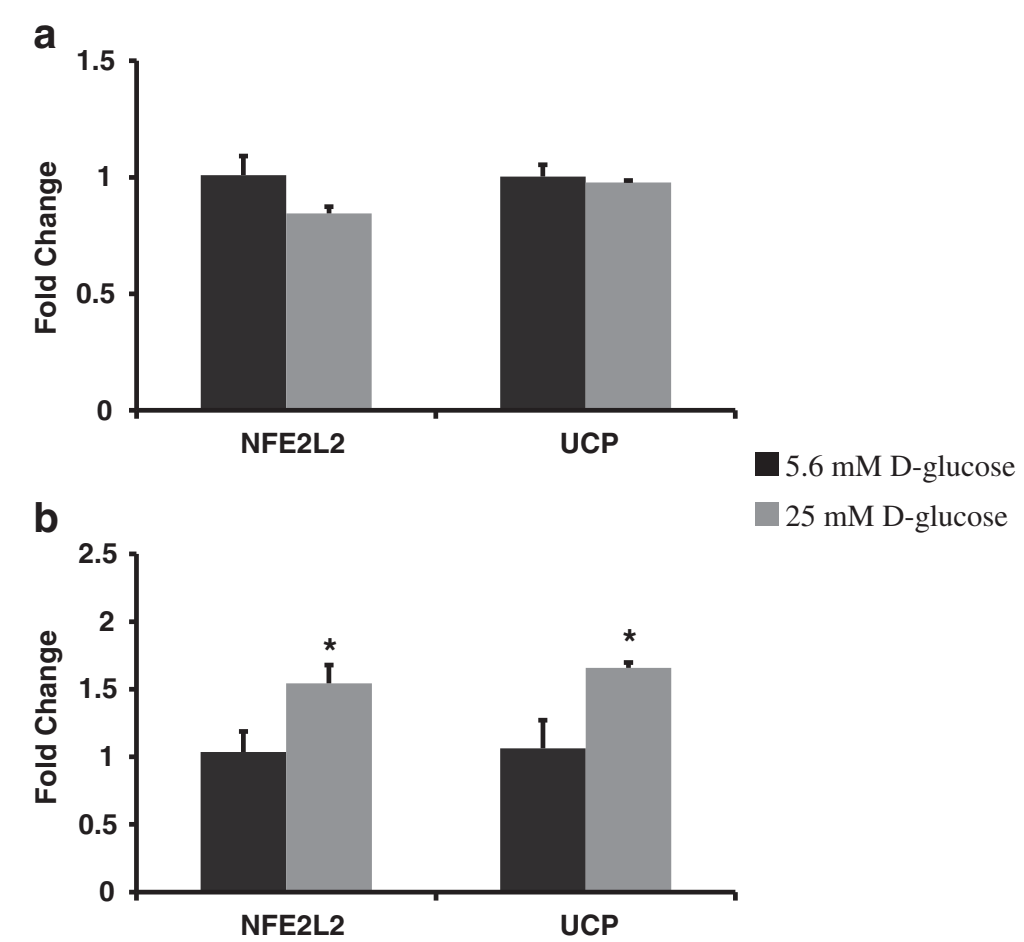

Figure 5 Expression levels of oxidative stress responding transcription factor and uncoupling protein in HUVEC, and HMVEC cells after 24 hours of high glucose exposure. Gene expression of NFE2L2 and UCP1 were measured in (a) HUVEC and (b) HMVEC following 24 hours of exposure to HG-M199. Fold changes were calculated by $2^{-\Delta \Delta C}$ method using $18 \mathrm{~s}$ and RPLP0 as housekeeping genes and cells grown in M199 media with $5.6 \mathrm{mM}$ D-glucose as control. ${ }^{*} \mathrm{p} \leq 0.06$ higher than control for HMVEC.

enzyme networks were affected in this study; resulting in an overall contribution to $\mathrm{O}_{2}^{-}$and $\mathrm{H}_{2} \mathrm{O}_{2}$ production. Moreover, limited correlation among protein translation, activity, and gene expression would not exclusively validate gene expression changes or vice versa [35-37].

Results from our study indicated that hyperglycemia induced consistent increase in $\mathrm{O}_{2}^{-}$production in both ECs. However, there was a differential change in underlying gene expression profile, $\mathrm{H}_{2} \mathrm{O}_{2}$ and mitochondrial membrane polarization levels during high glucose exposure in both ECs. A significant up-regulation in gene expression levels of NOS and NOX family enzymes, SOD1, CAT, GPX1, TXNRD1, TXNRD2, NFE2L2 and UCP1 were observed in HMVEC under high glucose exposure. On the contrary, HUVEC showed a down-regulation in SOD2 and CAT enzymes along with elevated $\mathrm{H}_{2} \mathrm{O}_{2}$ levels and hyperpolarized mitochondria.

\section{Hyperglycemia-induced differential NOS enzyme regulation in HUVEC and HMVEC}

Hyperglycemia results in endothelial dysfunction that may be a consequence of or cause of change in NOS expression and activity levels. Variable changes in NOS expression have been reported in the literature for hyperglycemicendothelial cells in cell cultures, animal models and humans [38]. We showed a non-significant downregulation and upregulation of NOSs expression in HUVEC and HMVEC, respectively. The expression levels of NOS3 have been have been reported to be up, down and no change in HUVEC [32,39]. Following 24 hours of high glucose exposure to HUVEC, we showed a non-significant downregulation in NOS3, which was similar to unchanged NOS3 levels reported by Zielonka et al. [32]. In HMVEC, we showed that the hyperglycemia induced an upregulation of NOS3 and NOS2 gene expression levels similar to previous study [40]. This differential NOS expression in HUVEC and HMVEC suggests a vasculature specific vasoregulatorygene expression regulation in hyperglycemia.

\section{Differential $N A D(P) H$ oxidase family enzyme regulated a} consistent $\mathrm{O}_{2}^{-}$production in high glucose treated HUVEC and HMVEC

Elevated $\mathrm{O}_{2}^{-}$levels serves as a hallmark to hyperglycemia mediated oxidative stress and vascular dysfunction $[6,29,32]$. We showed that DHE based measurement revealed increased $\mathrm{O}_{2}^{-}$levels in both endothelial cells. $\mathrm{NAD}(\mathrm{P}) \mathrm{H}$ oxidase family enzymes play a pivotal role in $\mathrm{O}_{2}^{-}$production in variety of endothelial cells during hyperglycemia [41]. Their ability to regulate $\mathrm{O}_{2}^{-}$production has been linked with their translocation to plasma membrane to co-localize with other enzyme units and increased activation under hyperglycemic condition [42-44]. 


\section{6mM D-glucose (Control)}
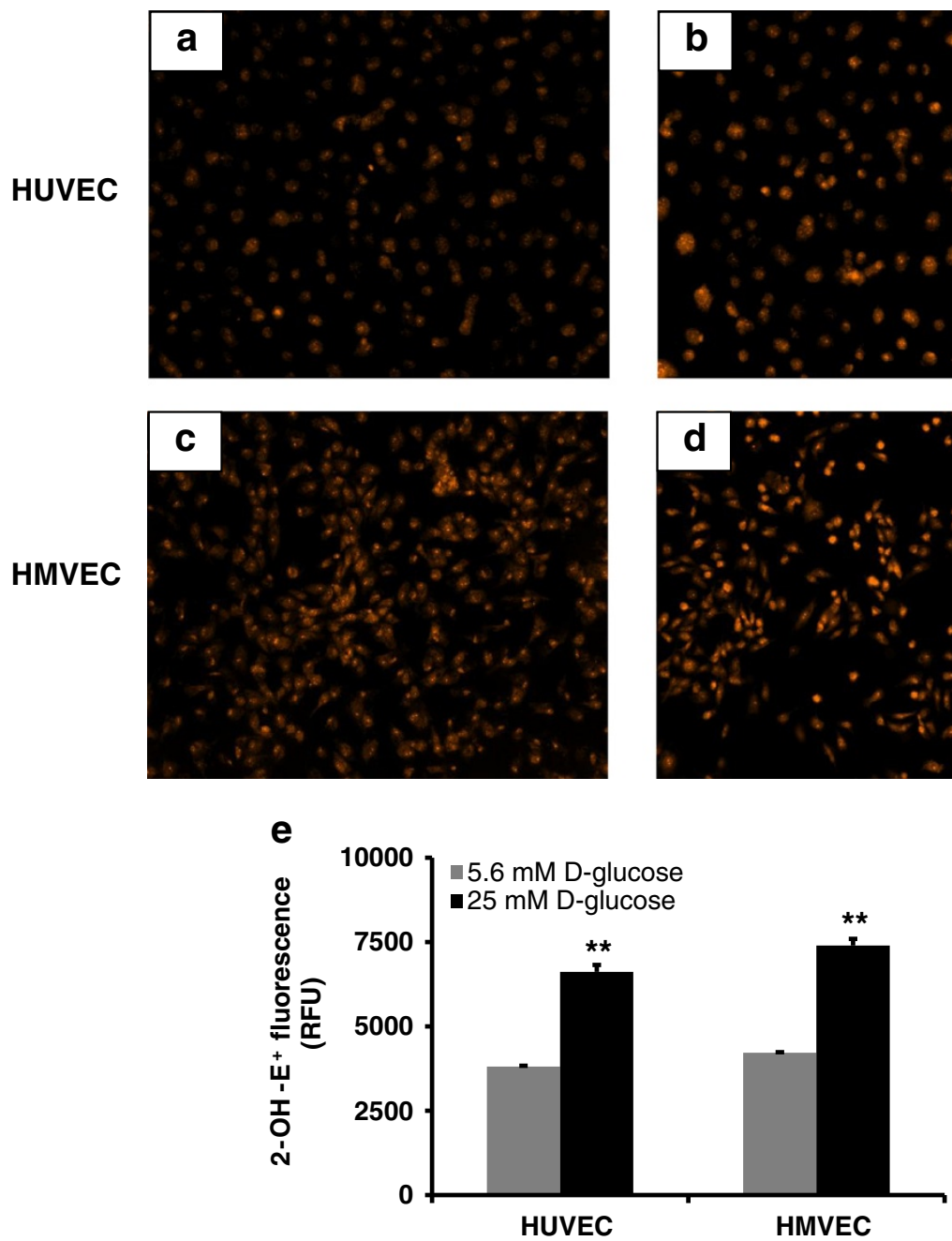

\section{HUVEC}

HIVEC
25mM D-glucose
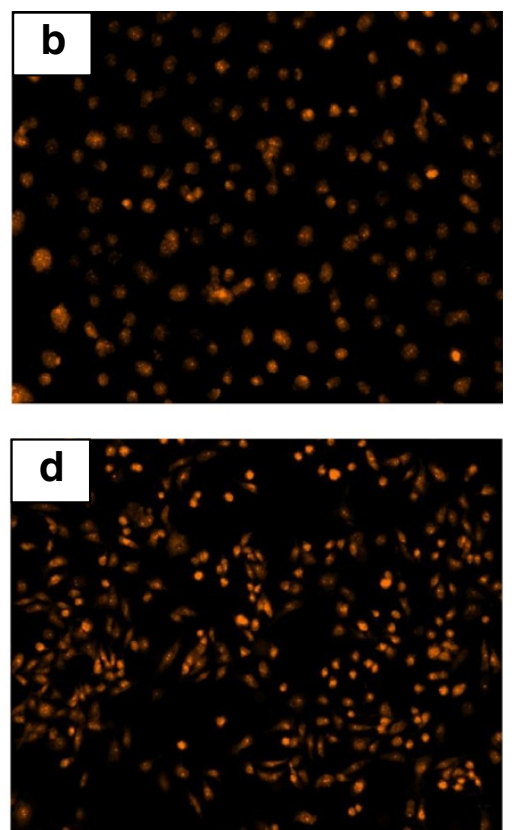

Figure $6 \mathrm{O}_{2}^{-}$production in HUVEC and HMVEC cells following high glucose exposure for $\mathbf{2 4}$ hours. Using DHE levels of $\mathrm{O}_{2}^{-}$were measured in both HUVEC and HMVEC following 24 hours of high glucose treatment. Fluorescence imaging was used to capture DHE fluorescence in (a-b) HUVEC and (c-d) HMVEC. Fluorescence microplate reader based measurements were also performed to measure specific fluorescence intensity of 2-OH-E in (e) HUVEC and HMVEC treated with high glucose. For both types of DHE measurements, cells grown in $5.6 \mathrm{mM}$ D-glucose were used as control. ${ }^{* *} \mathrm{p} \leq 0.01$ significantly higher than control for respective cells type.

Thus, even without any change in gene expression levels, as seen in our results, $\mathrm{NAD}(\mathrm{P}) \mathrm{H}$ oxidase family enzymes can regulate $\mathrm{O}_{2}^{-}$production in HUVEC. Additionally, eNOS uncoupling and mitochondrial ROS can contribute to increased cellular $\mathrm{O}_{2}{ }^{-}$, as seen in results $[14,45]$.

In our study, hyperpolarized mitochondrial membrane suggested the involvement of mitochondria in $\mathrm{O}_{2}^{-}$production in HUVEC. However, a depolarized mitochondrial membrane in hyperglycemic-HMVEC indicated involvement of non-mitochondrial $\mathrm{O}_{2}^{-}$production sources. Though the specific details of $\mathrm{O}_{2}^{-}$production sources in HMVEC are not available in the literature, our results suggested an increased involvement of $\mathrm{NAD}(\mathrm{P}) \mathrm{H}$ oxidase family enzyme (CYBA (non-significant), NOX1, and NOX4) in hyperglycemic HMVEC.

Along with increased involvement of $\mathrm{O}_{2}^{-}$production sources, we also showed downregulated SOD1 (non-significant) and SOD2 expression in HUVEC. Downregulated gene expressions of SODs were suggestive to reduced $\mathrm{O}_{2}{ }^{-}$ clearance in high glucose treated HUVEC. In HMVEC, gene expression of SOD1 and SOD2 (non-significant) simultaneously increased with $\mathrm{O}_{2}^{-}$levels, and CYBA (nonsignificant), NOX1, and NOX4 expression during hyperglycemia. Thus, hyperglycemia can induce regulation in gene expression of pro- and anti-oxidant sources resulting in increased $\mathrm{O}_{2}^{-}$levels through a complex interplay 


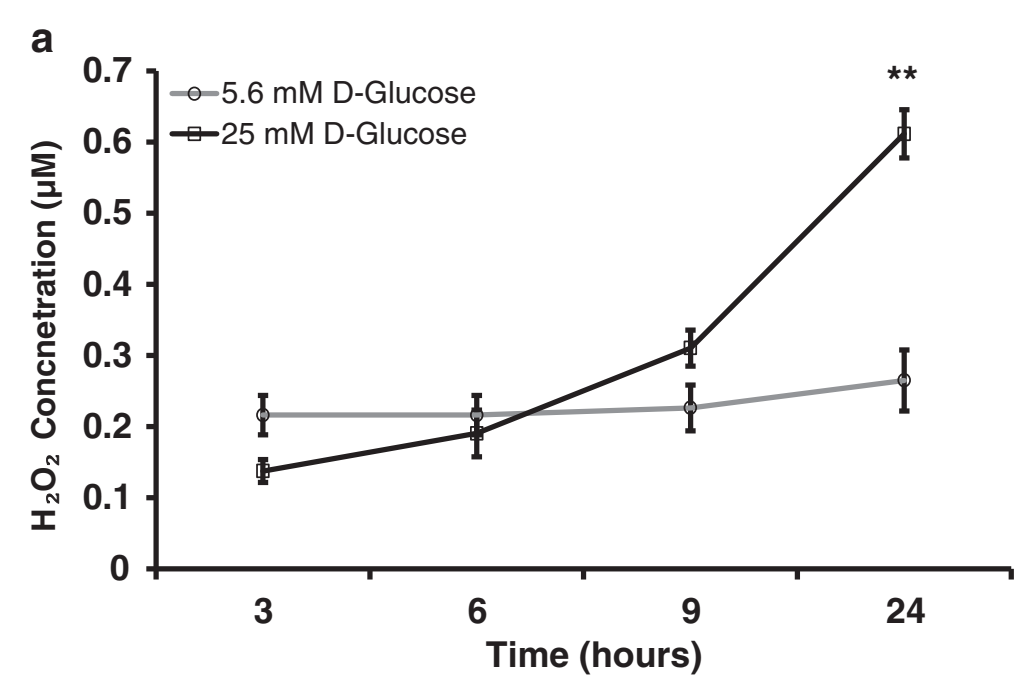

b

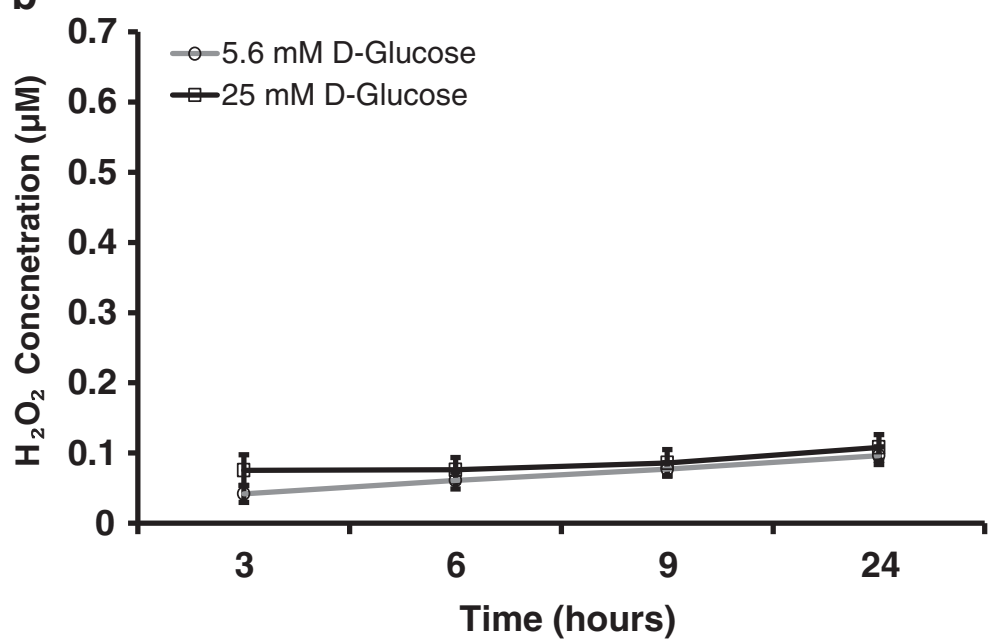

Figure $7 \mathrm{H}_{2} \mathrm{O}_{2}$ production profile in high glucose treated $\mathrm{HUVEC}$ and $\mathrm{HMVEC}$. Levels of $\mathrm{H}_{2} \mathrm{O}_{2}$ were measured in media supernatant of (a) HUVEC and (b) HMVEC treated with either $5.6 \mathrm{mM}$ (control) or $25 \mathrm{mM}$ D-glucose. Cells grown in media with 5.6 mM D-glucose were used as control. ${ }^{* *} p \leq 0.006$ significantly higher than control for respective cells type.

amongst them. Previous studies from our group have analyzed the complex interactions amongst oxidative stress and SOD [46,47]. Moreover, enzymatic activity regulation in pro- and anti-oxidant sources could also influenced increased $\mathrm{O}_{2}^{-}$levels as seen in high glucose treated HMVEC [36,37].

Interplay among mitochondrial membrane polarization and peroxidase clearance enzyme yielded to differential $\mathrm{H}_{2} \mathrm{O}_{2}$ in both endothelial cells

Excess production of $\mathrm{H}_{2} \mathrm{O}_{2}$ through rapid $\mathrm{O}_{2}^{-}$dismutation also contributes to hyperglycemia-dependent oxidative stress. $\mathrm{H}_{2} \mathrm{O}_{2}$ is one of the stable forms of free radicals during oxidative stress. However, $\mathrm{H}_{2} \mathrm{O}_{2}$ levels in hyperglycemic condition are variably reported in literature and hence its role in vasoregulatory activity remains unclear [38].
Consistent with the literature $[48,49]$, we showed increased levels of $\mathrm{H}_{2} \mathrm{O}_{2}$ in HUVEC. However, no-change was observed in $\mathrm{H}_{2} \mathrm{O}_{2}$ levels of HMVEC during high glucose exposure. Furthermore, we observed higher basal level $\mathrm{H}_{2} \mathrm{O}_{2}$ in HUVEC compared to HMVEC in controls. Under physiological condition, $\mathrm{H}_{2} \mathrm{O}_{2}$ promotes $\mathrm{NO}$ production and maintains cell growth [50,51]. Basal $\mathrm{H}_{2} \mathrm{O}_{2}$ levels are not well characterized across vasculature but our results suggests a possibility of higher basal production of $\mathrm{H}_{2} \mathrm{O}_{2}$ in macrovessel (HUVEC) compared to microvessel (HMVEC). The $\mathrm{H}_{2} \mathrm{O}_{2}$ levels are dependent on $\mathrm{O}_{2}^{-}$dismutation reaction, peroxide clearance, $\mathrm{NAD}(\mathrm{P}) \mathrm{H}$ oxidase activation and crosstalk with mitochondria, and mitochondrial hyperpolarization.

In HUVEC, downregulated SOD2 and CAT gene expression, similar as observed by Felice et al. [52], and 

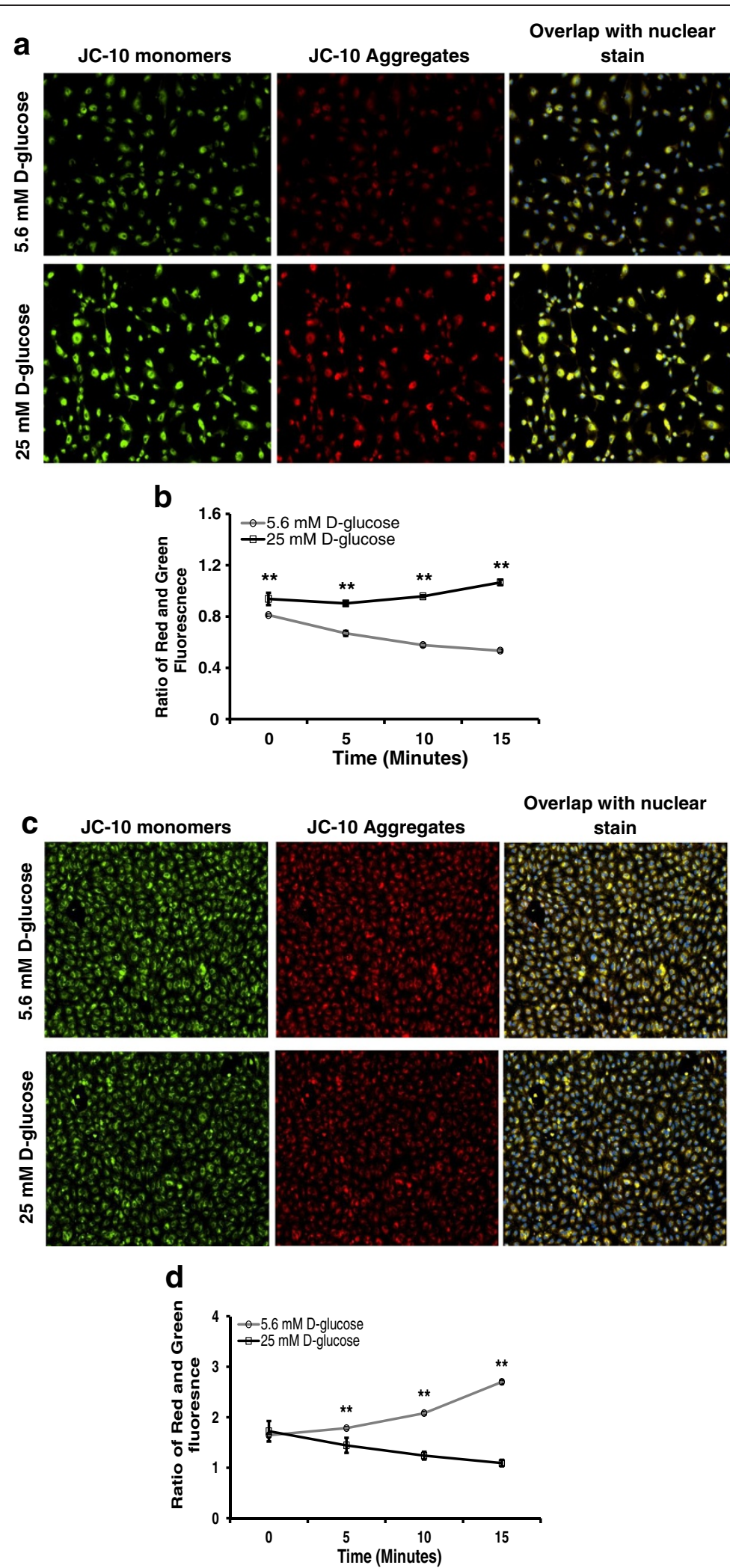

Figure 8 (See legend on next page.) 
(See figure on previous page.)

Figure 8 Mitochondrial membrane polarization in HUVEC and HMVEC following high glucose treatment for 24 hours. Using JC-10 mitochondrial membrane polarization was measured in both HUVEC and HMVEC after 24 hours of high glucose treatment. Mitochondrial membrane polarization of high glucose treated HUVEC was evaluated through measurement of JC-10 aggregates (Red) and monomers (Green) using fluorescence microscopy and microplate reader. a) Overlapped fluorescence images of red and green fluorescence intensities along with Hoescht-33342 based nuclear stain were used to show hyperpolarized mitochondrial membrane in high glucose treated HUVEC. b) Similarly, ratio of red and green fluorescence intensities were plotted to illustrate mitochondrial membrane hyperpolarization in high glucose treated HUVEC. ${ }^{* *} \mathrm{p} \leq 0.05$ significantly higher than $5.6 \mathrm{mM}$ D-glucose exposure treatment in HUVEC. c) Overlapped fluorescence images of red and green fluorescence intensities along with Hoescht-33342 based nuclear stain were used to show depolarized mitochondrial membrane in high glucose treated HMVEC. d) Ratio of red and green fluorescence intensities were plotted to show high glucose exposure-induced mitochondrial membrane depolarization in HMVEC. ${ }^{* *} \mathrm{p} \leq 0.05$ significantly higher than $25 \mathrm{mM}$ D-glucose exposure concentration in HMVEC.

their reduced activity under high glucose exposure, as shown by Zhang et al. [42], suggested decreased $\mathrm{O}_{2}^{-}$and $\mathrm{H}_{2} \mathrm{O}_{2}$ removal in HUVEC. As a result increased $\mathrm{H}_{2} \mathrm{O}_{2}$ level prevailed along with higher $\mathrm{O}_{2}^{-}$level in HUVEC following high glucose exposure. Moreover, hyperpolarized mitochondrial membrane, associated with increased $\mathrm{H}_{2} \mathrm{O}_{2}$ production, in HUVEC contributed to overall $\mathrm{H}_{2} \mathrm{O}_{2}$ levels in hyperglycemia [53]. Additionally, we observed downregulated (non-significant) gene expression levels of GPX1, TXNRD1, TXNRD2, PRDX1 and NFE2L2 in HUVEC, which plays a pivotal role in peroxidase clearance and promoting an anti-oxidative environment. Hyperglycemiainduced unaltered GPX1 was similar as reported by Felice et al. [52]. Not much detail is available in literature for hyperglycemia-induced gene expression of NFE2L2, TXNRD1, TXNRD2 and PRDX1 in HUVEC. In our results for HUVEC, hyperglycemia-induced regulation of these peroxidase clearance genes to pro-oxidative cellular environment and a reduced peroxide clearance.

Interestingly in contrast to HUVEC, the gene expression of ROS clearance enzymes, SOD1, GPX1, TXNRD1, TXNRD2, and PRDX1 were upregulated in HMVEC under hyperglycemia. ROS clearance transcription factor, NFE2L2 was also upregulated (though non-significant, $\mathrm{p}=0.06)$ under similar conditions. Upregulated SOD1 expression level suggests an increased $\mathrm{O}_{2}^{-}$processing to $\mathrm{H}_{2} \mathrm{O}_{2}$ in high glucose treated HMVEC. But simultaneous upregulation of GPX1, TXNRD1, TXNRD2, PRDX1 and NFE2L2 expression indicated a balanced increase in $\mathrm{H}_{2} \mathrm{O}_{2}$ clearance in high glucose treated HMVEC. Along with simultaneous expression of SOD1 and peroxide clearance enzymes, we observed no increase in $\mathrm{H}_{2} \mathrm{O}_{2}$ level indicating a predominant involvement of peroxide clearance enzymes in HMVEC under high glucose exposure. Additionally our results also showed depolarized mitochondrial membrane along with increased UCP1 gene expression, which has been shown to downplay mitochondrial $\mathrm{H}_{2} \mathrm{O}_{2}$ production in HMVEC [53]. Since there was not enough evidence in literature, we used our results from experiments using HUVEC as a reference to report these differential findings from HMVEC for the first time.

\section{Differential regulation of mitochondrial membrane polarization through UCP1 expression}

Uncoupling proteins (UCPs) are functionally linked to shunt electron transport chain and reduce mitochondrial membrane polarization in endothelial cells. Several studies explored this trait of UCPs by overexpressing UCP1, $\mathrm{UCP} 2$, and UCP3 to ameliorate mitochondrial hyperpolarization and hence to reduce ROS production in endothelial cells $[45,54]$. However, it was believed that UCP1 expression was exclusive to brown adipose tissue, but increasing number of recent studies have reported presence of UCP1 transcription in other tissues and specifically in endothelial cells from bovine and human retina [55]. In our results, we reported the presence of UCP1 transcription in both HUVEC and HMVEC. We also reported that hyperglycemia did not change UCP1 gene expression in HUVEC but upregulated it in HMVEC (though non-significant, $\mathrm{p}=0.06$ ). As observed by Nishikawa et al. [45,54], increased UCP1 gene expression observed in HMVEC can be linked to depolarized mitochondrial membrane and unchanged $\mathrm{H}_{2} \mathrm{O}_{2}$ production [53]. As the current state of literature is not clear on regulation and role of all UCPs in endothelial cells, it will be important to characterize gene expression of other UCPs in future studies.

\section{Hyperglycemia-induced differential epigenetic regulation in ECs from different vasculature}

Emerged concepts in vascular metabolic memory have explained limited efficacies of antihyperglycemic treatment and its late effect in type 2 diabetes [56]. The theories justifying such involvement of vascular metabolic memory have implicated non-reversible epigenetic regulation [57]. As observed in our results, 24 hours of hyperglycemiainduced differentially regulated gene expression in HUVEC and HMVEC. In specific, high occurrences of gene expression changes in HMVEC in our study provided the evidence for the hypothesis in vascular metabolic memory that suggests microvasculature precedes macrovasculature in epigenetic regulation forming vascular metabolic memory [58]. Such differential regulation, even from short exposure, may explain non-uniform epigenetic regulation 
across vasculature. Further research will be of importance to understand the involvement of vasculature specific pathologies and the role of vascular metabolic memory in endothelial dysfunction.

\section{Conclusion}

In conclusion, we studied the pro and anti-oxidant sources contributions under hyperglycemic endothelial cell oxidative stress. Hyperglycemia induced a pro-oxidative environment in both HUVEC and HMVEC through increased $\mathrm{O}_{2}^{-}$production. We demonstrated that ECs have differential involvement of oxidative stress regulating mechanisms from NOS enzymes, NAD $(\mathrm{P}) \mathrm{H}$ oxidase enzymes, ROS clearance enzymes and antioxidant gene expression in hyperglycemia that results in significantly different outcome of mitochondrial membrane polarization and $\mathrm{H}_{2} \mathrm{O}_{2}$ level. Such interplay among key enzyme gene expression, mitochondrial membrane polarization and $\mathrm{O}_{2}^{-}$and $\mathrm{H}_{2} \mathrm{O}_{2}$ level regulation indicated the complexity of processes that regulates vasculature specific endothelial behavior in hyperglycemia. High occurrences of gene expression changes in HMVEC in this study supports the hypothesis that microvasculature precedes macrovasculature in epigenetic regulation forming vascular metabolic memory. Identifying genomic phenotype and corresponding functional changes in hyperglycemic endothelial dysfunction will provide a suitable systems biology approach for understanding underlying mechanisms and possible effective therapeutic intervention.

\footnotetext{
Abbreviations

$\mathrm{O}_{2}$-: Superoxide; $\mathrm{H}_{2} \mathrm{O}_{2}$ : Hydrogen peroxide; ROS: Reactive oxygen species; DHE: Dihydroethidium; NO: Nitric oxide; EC: Endothelial cell;

eNOS: Constitutive nitric oxide synthase; SOD: Superoxide dismutase; NOX4: NAD(P)H oxidase-4; HUVEC: Human umbilical vein endothelial cell; HAEC: Human aortic endothelial cell, HREC, Human retinal endothelial cell; HGEC: Human glomerular endothelial cells; HMEC-1: Human microvascular endothelial cells; HMVEC: Human dermal microvasculature endothelial cell; SOD1: Superoxide dismutase 1; SOD2: Superoxide dismutase 2; CAT: Catalase; PRDX1: Peroxiredoxin; GPX1: Glutathione peroxidase 1; TXNRD1: Thioredoxin reductase 1; TXNRD2: Thioredoxin reductase 1; NFE2L2: Oxidative stress activated transcription factor, Nrf-2; UCP1: Uncoupling protein 1; HGM199: 25mM D-glucose added M199; DHE: Dihydroethidium; 2-OH-E 2-hydroxyethidium; Ex: Excitation; Em: Emission; ANOVA: Analysis of variance; S.E.M.: Standard error of mean; UCPs: Uncoupling proteins.
}

\section{Competing interests}

No potential conflicts of interest relevant to this article were reported.

\section{Authors' contributions}

$\mathrm{HP}$ designed study, researched gene expression, $\mathrm{H}_{2} \mathrm{O}_{2}$ and mitochondrial membrane polarization measurement data, performed statistical analysis, performed literature search and drafted manuscript. JC researched $\mathrm{O}_{2}^{-}$ production results. HP and JC are the guarantor of this work and takes responsibility for the integrity of the data and accuracy of the data analysis. KD reviewed manuscript. MK reviewed and edited manuscript. All authors approved the final manuscript for publication.

\section{Acknowledgements}

This study was funded by NIH R01 HL084337. We thank Sarah Daoud for her assistance to establish mitochondrial membrane polarization measurement procedure.

\section{Author details}

${ }^{1}$ Department of Biomedical Engineering, Wayne State University, 2322 Engineering, 5050 Anthony Wayne Dr., Detroit, MI 48202, USA. ²Department of Anesthesiology, Texas Tech University Health Sciences Center, Lubbock, TX 79430, USA.

Received: 1 August 2013 Accepted: 4 October 2013

Published: 5 October 2013

\section{References}

1. Haring R, Wallaschofski H, Nauck M, Felix SB, Schmidt CO, Dorr M, Sauer S, Wilmking G, Volzke $\mathrm{H}$ : Total and cardiovascular disease mortality predicted by metabolic syndrome is inferior relative to its components. Exp Clin Endocrinol Diab 2010, 118(10):685-691.

2. Versari D, Daghini E, Virdis A, Ghiadoni L, Taddei S: Endothelial dysfunction as a target for prevention of cardiovascular disease. Diab Care 2009, 32(Suppl 2):S314-S321.

3. Kassab A, Piwowar A: Cell oxidant stress delivery and cell dysfunction onset in type 2 diabetes. Biochimie 2012, 94(9):1837-1848.

4. Hadi HA, Carr CS, Al Suwaidi J: Endothelial dysfunction: cardiovascular risk factors, therapy, and outcome. Vasc Health Risk Manage 2005, 1(3):183-198.

5. Anderson TJ: Assessment and treatment of endothelial dysfunction in humans. J Am Coll Cardiol 1999, 34(3):631-638.

6. Tousoulis D, Briasoulis A, Papageorgiou N, Tsioufis C, Tsiamis E, Toutouzas K, Stefanadis C: Oxidative stress and endothelial function: therapeutic interventions. Recent Pat Cardiovasc Drug Discov 2011, 6(2):103-114.

7. Taddei S, Virdis A, Ghiadoni L, Sudano I, Salvetti A: Effects of antihypertensive drugs on endothelial dysfunction: clinical implications. Drugs 2002, 62(2):265-284.

8. Colagiuri S: Diabesity: therapeutic options. Diab Obes Metab 2010, 12(6):463-473.

9. Potdar S, Kavdia M: NO/peroxynitrite dynamics of high glucose-exposed HUVECs: chemiluminescent measurement and computational model. Microvasc Res 2009, 78(2):191-198.

10. Silva BR, Pernomian L, Bendhack LM: Contribution of oxidative stress to endothelial dysfunction in hypertension. Front Physiol 2012, 3:441.

11. Jansen F, Yang X, Franklin BS, Hoelscher M, Schmitz T, Bedorf J, Nickenig G, Werner N: High glucose condition increases NADPH oxidase activity in endothelial microparticles that promote vascular inflammation. Cardiovasc Res 2013, 98(1):94-106.

12. Zhou ZW, Xie XL, Zhou SF, Li CG: Mechanism of reversal of high glucoseinduced endothelial nitric oxide synthase uncoupling by tanshinone IIA in human endothelial cell line EA.hy926. Eur J Pharmacol 2012, 697(1-3):97-105.

13. Shen GX: Oxidative stress and diabetic cardiovascular disorders: roles of mitochondria and NADPH oxidase. Can J Physiol Pharmacol 2010, 88(3):241-248

14. Kar S, Kavdia M: Modeling of biopterin-dependent pathways of eNOS for nitric oxide and superoxide production. Free Radic Biol Med 2011, 51(7):1411-1427.

15. Thomas SR, Chen K, Keaney JF Jr: Hydrogen peroxide activates endothelial nitric-oxide synthase through coordinated phosphorylation and dephosphorylation via a phosphoinositide 3-kinase-dependent signaling pathway. J Biol Chem 2002, 277(8):6017-6024.

16. Ray R, Murdoch CE, Wang M, Santos CX, Zhang M, Alom-Ruiz S, Anilkumar N, Ouattara A, Cave AC, Walker SJ, et al: Endothelial Nox4 NADPH oxidase enhances vasodilatation and reduces blood pressure in vivo. Arterioscler Thromb Vasc Biol 2011, 31(6):1368-1376.

17. Quijano C, Castro L, Peluffo G, Valez V, Radi R: Enhanced mitochondrial superoxide in hyperglycemic endothelial cells: direct measurements and formation of hydrogen peroxide and peroxynitrite. Am J Physiol Heart Circ Physiol 2007, 293(6):H3404-H3414.

18. Lucchesi PA, Belmadani S, Matrougui K: Hydrogen peroxide acts as both vasodilator and vasoconstrictor in the control of perfused mouse mesenteric resistance arteries. J Hypertens 2005, 23(3):571-579.

19. Zhang DX, Gutterman DD: Mitochondrial reactive oxygen speciesmediated signaling in endothelial cells. Am J Physiol Heart Circ Physiol 2007, 292(5):H2023-H2031.

20. Singh S, Vrishni S, Singh BK, Rahman I, Kakkar P: Nrf2-ARE stress response mechanism: a control point in oxidative stress-mediated dysfunctions and chronic inflammatory diseases. Free Radic Res 2010, 44(11):1267-1288. 
21. Geenen IL, Molin DG, van den Akker NM, Jeukens F, Spronk HM, Schurink GW, Post MJ: Endothelial cells (ECs) for vascular tissue engineering: venous ECs are less thrombogenic than arterial ECs. J Tissue Eng Regen Med 2012. Epub ahead of print

22. Zamora DO, Riviere M, Choi D, Pan Y, Planck SR, Rosenbaum JT, David LL, Smith JR: Proteomic profiling of human retinal and choroidal endothelial cells reveals molecular heterogeneity related to tissue of origin. Molecular vision 2007, 13:2058-2065.

23. Salcedo R, Resau JH, Halverson D, Hudson EA, Dambach M, Powell D, Wasserman $\mathrm{K}$, Oppenheim JJ: Differential expression and responsiveness of chemokine receptors (CXCR1-3) by human microvascular endothelial cells and umbilical vein endothelial cells. FASEB J 2000, 14(13):2055-2064.

24. Wang XH, Chen SF, Jin HM, Hu RM: Differential analyses of angiogenesis and expression of growth factors in micro- and macrovascular endothelial cells of type 2 diabetic rats. Life Sci 2009, 84(7-8):240-249.

25. Xue M, Qian Q, Adaikalakoteswari A, Rabbani N, Babaei-Jadidi R, Thornalley PJ: Activation of NF-E2-related factor-2 reverses biochemical dysfunction of endothelial cells induced by hyperglycemia linked to vascular disease. Diabetes 2008, 57(10):2809-2817.

26. Cifarelli V, Geng X, Styche A, Lakomy R, Trucco M, Luppi P: C-peptide reduces high-glucose-induced apoptosis of endothelial cells and decreases $\mathrm{NAD}(\mathrm{P}) \mathrm{H}$-oxidase reactive oxygen species generation in human aortic endothelial cells. Diabetologia 2011, 54(10):2702-2712.

27. Castilho A, Aveleira CA, Leal EC, Simoes NF, Fernandes CR, Meirinhos RI, Baptista Fl, Ambrosio AF: Heme oxygenase-1 protects retinal endothelial cells against high glucose- and oxidative/nitrosative stress-induced toxicity. Plos one 2012, 7(8):e42428.

28. Hoshiyama M, Li B, Yao J, Harada T, Morioka T, Oite T: Effect of high glucose on nitric oxide production and endothelial nitric oxide synthase protein expression in human glomerular endothelial cells. Nephron Exp Nephrol 2003, 95(2):e62-e68.

29. Karbach S, Jansen T, Horke S, Heeren T, Scholz A, Coldewey M, Karpi A Hausding M, Kroller-Schon S, Oelze M, et al: Hyperglycemia and oxidative stress in cultured endothelial cells-a comparison of primary endothelial cells with an immortalized endothelial cell line. J Diab Complications 2012, 26(3):155-162.

30. Pala L, Pezzatini A, Dicembrini I, Ciani S, Gelmini S, Vannelli BG, Cresci B, Mannucci E, Rotella CM: Different modulation of dipeptidyl peptidase-4 activity between microvascular and macrovascular human endothelial cells. Acta Diabetol 2012, 49(Suppl 1):S59-S63.

31. Krentz AJ, Clough G, Byrne CD: Interactions between microvascular and macrovascular disease in diabetes: pathophysiology and therapeutic implications. Diab Obes Metab 2007, 9(6):781-791.

32. Zielonka J, Zielonka M, Sikora A, Adamus J, Joseph J, Hardy M, Ouari O, Dranka BP, Kalyanaraman B: Global profiling of reactive oxygen and nitrogen species in biological systems: high-throughput real-time analyses. J Biol Chem 2012, 287(5):2984-2995.

33. Nazarewicz RR, Bikineyeva A, Dikalov SI: Rapid and specific measurements of superoxide using fluorescence spectroscopy. J Biomol Screen 2013, 18(4):498-503

34. Chen J, Rogers SC, Kavdia M: Analysis of kinetics of dihydroethidium fluorescence with superoxide using xanthine oxidase and hypoxanthine assay. Ann Biomed Eng 2013, 41(2):327-337.

35. Vogel C, Marcotte EM: Insights into the regulation of protein abundance from proteomic and transcriptomic analyses. Nat Rev Genet 2012, 13(4):227-232.

36. Noyman I, Marikovsky M, Sasson S, Stark AH, Bernath K, Seger R, Madar Z Hyperglycemia reduces nitric oxide synthase and glycogen synthase activity in endothelial cells. Nitric Oxide 2002, 7(3):187-193.

37. Du XL, Edelstein D, Dimmeler S, Ju Q, Sui C, Brownlee M: Hyperglycemia inhibits endothelial nitric oxide synthase activity by posttranslational modification at the Akt site. J Clin Invest 2001, 108(9):1341-1348.

38. Bayraktutan U: Free radicals, diabetes and endothelial dysfunction. Diab Obes Metab 2002, 4(4):224-238.

39. Liu J, Wei S, Tian L, Yan L, Guo Q, Ma X: Effects of endomorphins on human umbilical vein endothelial cells under high glucose. Peptides 2011, 32(1):86-92

40. Farhangkhoee $\mathrm{H}$, Khan ZA, Chen S, Chakrabarti S: Differential effects of curcumin on vasoactive factors in the diabetic rat heart. Nutr Metab 2006, 3:27.
41. Lassegue B, San Martin A, Griendling KK: Biochemistry, physiology, and pathophysiology of NADPH oxidases in the cardiovascular system. Circ Res 2012, 110(10):1364-1390.

42. Zhang Z, Yang Z, Zhu B, Hu J, Liew CW, Zhang Y, Leopold JA, Handy DE, Loscalzo J, Stanton RC: Increasing glucose 6-phosphate dehydrogenase activity restores redox balance in vascular endothelial cells exposed to high glucose. PLoS One 2012, 7(11):e49128.

43. Chen F, Qian LH, Deng B, Liu ZM, Zhao Y, Le YY: Resveratrol Protects Vascular Endothelial Cells from High Glucose-Induced Apoptosis through Inhibition of NADPH Oxidase Activation-Driven Oxidative Stress. CNS Neurosci Ther 2013, 19(9):675-681.

44. Block K, Gorin Y, Abboud HE: Subcellular localization of Nox4 and regulation in diabetes. Proc Natl Acad Sci U S A 2009, 106(34):14385-14390.

45. Nishikawa T, Araki E: Impact of mitochondrial ROS production in the pathogenesis of diabetes mellitus and its complications. Antioxid Redox Signal 2007, 9(3):343-353

46. Kar S, Kavdia M: Endothelial NO and $\mathrm{O}(2) .(-)$ production rates differentially regulate oxidative, nitroxidative, and nitrosative stress in the microcirculation. Free Radic Biol Med 2013, 63:161-174.

47. Kar S, Bhandar B, Kavdia M: Impact of SOD in eNOS uncoupling: a twoedged sword between hydrogen peroxide and peroxynitrite. Free Radic Res 2012, 46(12):1496-1513.

48. Yang Z, Mo X, Gong Q, Pan Q, Yang X, Cai W, Li C, Ma JX, He Y, Gao G: Critical effect of VEGF in the process of endothelial cell apoptosis induced by high glucose. Apoptosis 2008, 13(11):1331-1343.

49. Hsu CC, Yin MC, Tian R: Ascorbic acid and uric acid suppress glucoseinduced fibronectin and vascular endothelial growth factor production in human endothelial cells. J Diabetes Complications 2005, 19(2):96-100.

50. Oshikawa J, Urao N, Kim HW, Kaplan N, Razvi M, McKinney R, Poole LB, Fukai T, Ushio-Fukai M: Extracellular SOD-derived $\mathrm{H} 2 \mathrm{O} 2$ promotes VEGF signaling in caveolae/lipid rafts and post-ischemic angiogenesis in mice. Plos One 2010, 5(4):e10189.

51. Cai $\mathrm{H}$ : Hydrogen peroxide regulation of endothelial function: origins, mechanisms, and consequences. Cardiovasc Res 2005, 68(1):26-36.

52. Felice F, Lucchesi D, di Stefano R, Barsotti MC, Storti E, Penno G, Balbarini A, Del Prato S, Pucci L: Oxidative stress in response to high glucose levels in endothelial cells and in endothelial progenitor cells: evidence for differential glutathione peroxidase-1 expression. Microvascular research 2010, 80(3):332-338.

53. Naudi A, Jove M, Ayala V, Cassanye A, Serrano J, Gonzalo H, Boada J, Prat J, Portero-Otin M, Pamplona R: Cellular dysfunction in diabetes as maladaptive response to mitochondrial oxidative stress. Exp Diabetes Res 2012, 2012:696215

54. Nishikawa T, Edelstein D, Du XL, Yamagishi S, Matsumura T, Kaneda Y, Yorek MA, Beebe D, Oates PJ, Hammes HP, et al: Normalizing mitochondrial superoxide production blocks three pathways of hyperglycaemic damage. Nature 2000, 404(6779):787-790.

55. Brondani LA, de Souza BM, Duarte GC, Kliemann LM, Esteves JF, Marcon AS, Gross JL, Canani LH, Crispim D: The UCP1-3826A/G polymorphism is associated with diabetic retinopathy and increased UCP1 and MnSOD2 gene expression in human retina. Invest Ophthalmol Vis Sci 2012, 53(12):7449-7457.

56. Jermendy G: Vascular memory: can we broaden the concept of the metabolic memory? Cardiovasc Diabetol 2012, 11(1):44.

57. Bianchi C, Miccoli R, Del Prato S: Hyperglycemia and Vascular Metabolic Memory: Truth or Fiction? Curr Diabetes Rep 2013, 13(3):403-410.

58. Jax TW: Metabolic memory: a vascular perspective. Cardiovasc Diabetol 2010, 9:51.

doi:10.1186/1475-2840-12-142

Cite this article as: Patel et al: Hyperglycemia induces differential change in oxidative stress at gene expression and functional levels in HUVEC and HMVEC. Cardiovascular Diabetology 2013 12:142. 